\title{
Multi-modality imaging evaluation of recurrent Tako-tsubo syndrome in a patient with coronary artery fibromuscular dysplasia
}

Yun Cheng, Chenying Lu and Kan Liu*

\begin{abstract}
Background: Integrated bedside and sophisticated cardiac imaging techniques help characterize the discrepancy between myocardial injury and mechanic dysfunction in acute myocardial infarction.

Case presentation: A 57 year-old woman presented with sudden onset chest pain and ventricular fibrillation after hearing of her brother's death. The electrocardiography indicated "anterior wall ST segment elevation myocardial infarction". Coronary angiography ruled out obstructive lesion in the major coronary arteries, but revealed fibromuscular dysplasia of the distal left anterior descending artery. The ventriculography showed remarkable ventricular dilation, which affected much broader myocardium than the culprit vessel supplied. In a subsequent cardiac magnetic resonance study, delayed contrast (gadolinium) image revealed a focal left ventricular (LV) apical infarction. Her LV systolic function normalized within 1 week, except for a residual apical hypokinesis. She developed recurrent chest pain and LV dilation when she was laid off 9 months later. After supportive therapy, her symptoms improved and LV dysfunction normalized again.
\end{abstract}

Conclusions: "Tako-tsubo" syndrome can occur recurrently in the heart with pre-existing localized myocardial infarction. Its molecular mechanism and clinical significance warrants further investigation.

\section{Background}

Although its clinical manifestation often mimics that of an acute anterior wall myocardial infarction (MI), Takotsubo syndrome (TTS) was postulated to have completely different etiology, pathophysiology and prognosis $[1,2]$. As more real-time cardiac imaging, particularly bedside echocardiography, are applied, TTS have been frequently identified in patients with coexisting coronary artery disease. Multi-modality imaging evaluation help characterize the discrepancy between myocardial injury and ventricular mechanic dysfunction during TTS and MI.

\section{Case presentation}

A 57 year-old woman presented with sudden onset chest pain/ventricular fibrillation after hearing of her brother's

* Correspondence: liuk@upstate.edu

State University of New York, Upstate Medical University, Syracuse, NY 13202, USA

death. The electrocardiography indicated "anterior wall ST segment elevation myocardial infarction". Laboratory data was notable for cTnT $1.12 \mathrm{ng} / \mathrm{mL}$. Coronary angiography ruled out obstructive lesion in the major coronary arteries, but revealed a tapering and long narrowing distal left anterior descending artery (LAD, Fig. 1a and b), which was consistent with angiographic feature of coronary artery fibromuscular dysplasia [3]. The ventriculography showed remarkable ventricular dilation, which affected much broader myocardium than the culprit vessel supplied (Fig. 1c, arrowheads). In a subsequent cardiac magnetic resonance (CMR) study, left ventricular (LV) remained dilated (Fig. 1d). Delayed contrast (gadolinium) image confirmed a localized mayocardial infarc-

One week later, repeated transthoracic echocardiography (TTE) showed nearly normalized LV systolic function except for a residual apical hypokinesis (Fig. $1 \mathrm{~h}-\mathrm{n}$ ) compared with original episode (Fig. 1g-m). 

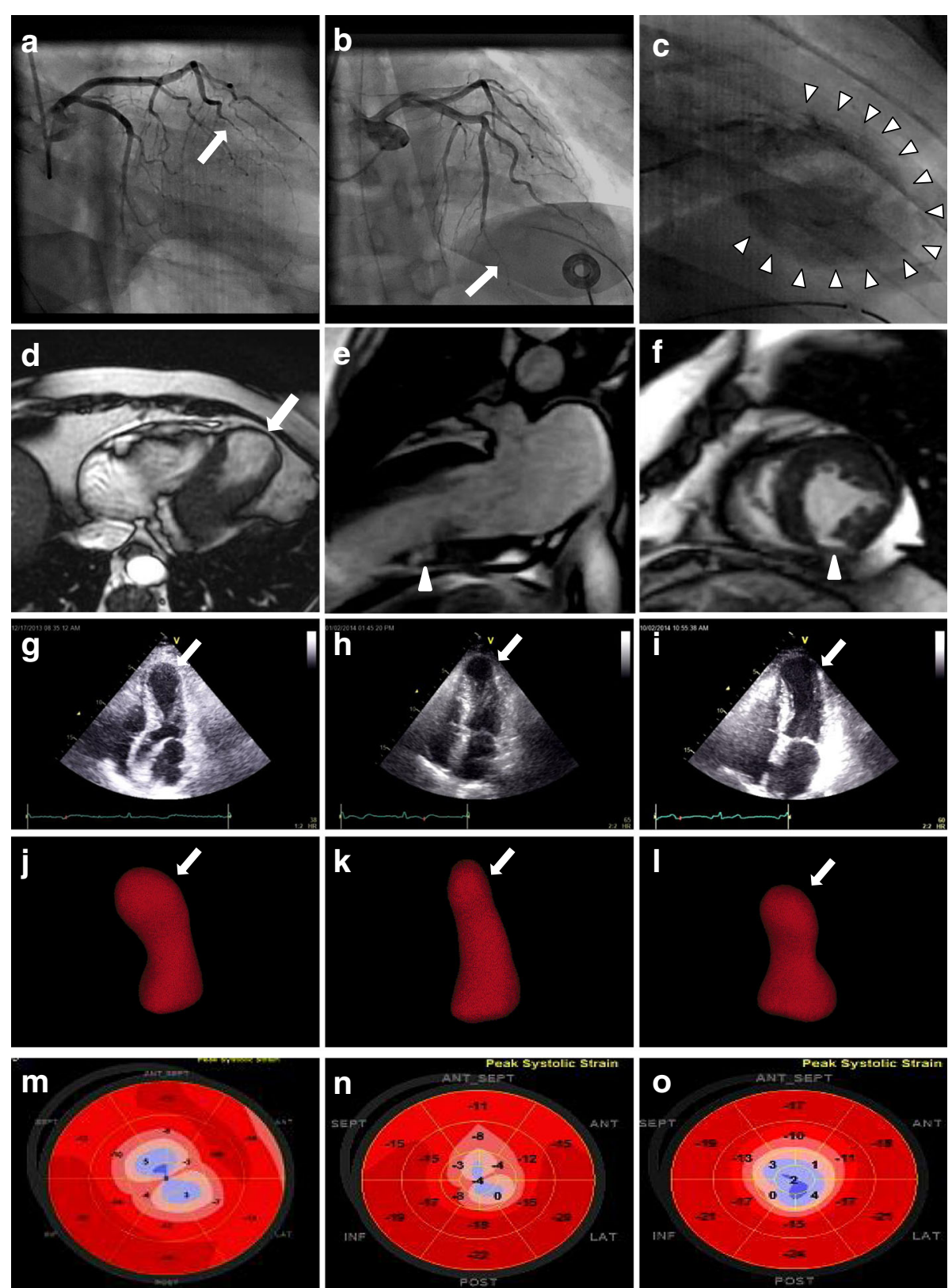

Fig. 1 Recurrent Tako-tsubo syndrome (TTS) in a woman with coronary artery fibromuscular dysplasia and left ventricular apical infarction. a (right anterior oblique caudal projection) and (b) (right anterior oblique cranial projection): The coronary angiograms showing a tapering and smooth narrowing (with a discrete transition from normal to diseased artery) in distal left anterior descending artery (arrows) .c The Ventriculography (right anterior oblique projection) demonstrating apical ballooning involving broader myocardium beyond the territory of distal LAD (arrowheads). d Non-contrast cardiac magnetic resonance (CMR) images indicating dilated left ventricle (arrow). e Two chamber view contrast CMR with late gadolinium enhancement (LGE) image revealing localized inferoapical myocardial infarction (arrowhead). f Short-axis view contrast CMR with LGE image revealing localized inferoapical apical myocardial infarction (arrowhead). g-o Recurrent TTS with alternated ventricular contractile patterns. $\mathbf{g}, \mathbf{h}, \mathbf{i}$ Two dimensional echocardiograms; (j, k, l): Three-dimensional echocardiograms; M,N,O: Speckle tracking echocardiograms (automated function imaging with a "bull's eye" plot). $\mathbf{g}$, j, and $\mathbf{m}$ : Initial TTS; (h), (k) and (n): recovery period; (i), (I), and (o): recurrent TTS

Nine months later, when she was laid off, she developed recurrent chest pain and significant LV dilation, with different contractile pattern (Fig. 1i-o). With only supportive therapy, both her symptoms and LV dysfunction spontaneously improved quickly.

\section{Discussion}

The present case illustrates a unique scenario, in which TTS occur recurrently in the heart with pre-existing localized myocardial infarction. In contrast to "gatekeeper" role of bedside echocardiography, advanced 
cardiac imaging has improved the tomographic visualization and our understanding on myocardial injury/metabolism in both TTS [4, 5] and MI [6]. During acute MI, psychological stress and/or physical pain can stimulate central/autonomic nervous systems, and increase bioavailability of cortisol and circulating catecholamines, which may affect the myocardium supported by both culprit and non-culprit coronary arteries.

In the presence of coronary artery disorder, is hypocontractile myocardium beyond the myocardial territory of the culprit coronary artery a coincidence, or a causeand-effect? Also, its clinical significance remains unknown. Molecular research has revealed that TTS is mediated by a cardio-protective switching of epinephrine signaling transduction through the pleiotropic $\beta_{2}$-adrenergic receptors [7]. Whether the TTS during and/ or after MI represents a universal physiologically adaptive response of a jeopardized heart warrants further investigation.

\section{Conclusions}

TTS occurs recurrently in a patient with pre-existing localized myocardial infarction caused by coronary artery fibromyscular dysplasia.

\section{Abbreviations}

CMR: Cardiac magnetic resonance; ECG: Electrocardiogram; LAD: Left anterior descending artery; MI: Myocardial infarction; STEMI: ST segment myocardial infarction; TTE: Transthoracic echocardiography; TTS: Tako-tsubo syndrome

\section{Acknowledgements}

Not applicable

\section{Funding}

Not applicable

\section{Availability of data and materials \\ Yes}

\section{Authors' contributions}

$Y C, C L$, and $K L$ had full access to all the data in the study and take responsibility for the integrity of the data and the accuracy of the data analysis, including and especially any adverse effects. All of authors helped write or edit the manuscript. All authors read and approved the final manuscript.

\section{Authors' information}

All author details on the revised version are correct, that all authors have agreed to authorship and order of authorship for this manuscript and that all authors have the appropriate permissions and rights to the reported data.

\section{Ethics approval and consent to participate}

Written informed consent was obtained from the patient for the publication of the individual details and accompanying images in this manuscript. The consent form is held by the authors and is available for review.

\section{Consent for publication}

Yes

\section{Competing interests}

The authors declare that they have no competing interests.

\section{Publisher's Note}

Springer Nature remains neutral with regard to jurisdictional claims in published maps and institutional affiliations.

Received: 23 October 2017 Accepted: 13 November 2017

Published online: 30 November 2017

\section{References}

1. Templin C, Ghadri JR, Diekmann J, Napp LC, Bataiosu DR, Jaguszewski M, et al. Clinical features and outcomes of Takotsubo (stress) cardiomyopathy. N Engl J Med. 2015;373:929-38.

2. Lyon AR, Bossone E, Schneider B, Sechtem U, Citro R, Underwood SR, Sheppard MN, Figtree GA, Parodi G, Akashi YJ, Ruschitzka F, Filippatos G, Mebazaa A, Omerovic E. Current state of knowledge on Takotsubo syndrome: a position statement from the taskforce on Takotsubo syndrome of the heart failure Association of the European Society of cardiology. Eur J Heart Fail. 2016;18:8-27.

3. Michelis KC, Olin JW, Kadian-Dodov D, d'Escamard V, Kovacic JC. Coronary artery manifestations of fibromuscular dysplasia. J Am Coll Cardiol. 2014;64: 1033-46.

4. Christensen TE, Ahtarovski KA, Bang LE, Holmvang L, Søholm H, Ghotbi AA, et al. Basal hyperaemia is the primary abnormality of perfusion in Takotsubo cardiomyopathy: a quantitative cardiac perfusion positron emission tomography study. Eur Heart J Cardiovasc Imaging. 2015;16:1162-9.

5. Sun ZX, Singh P, Wei TM, Kozman H, Liu K. Is the heart really stressed out of energy? J Am Coll Cardiol: Cardiovasc Imaging. 2016:9:633-5.

6. Bulluck H, White SK, Fröhlich GM, Casson SG, O Meara C, Newton A, et al. Quantifying the Area at Risk in Reperfused ST-Segment-Elevation Myocardial Infarction Patients Using Hybrid Cardiac Positron Emission TomographyMagnetic Resonance Imaging CLINICAL PERSPECTIVE Circulation: Cardiovascular Imaging 2016; 9: e3900. DOI: 10.1161/CIRCIMAGING.115.003900.

7. Paur H, Wright PT, Sikkel MB, Tranter MH, Mansfield C, O'Gara P, et al. High levels of circulating epinephrine trigger apical cardiodepression in a beta2adrenergic receptor/Gi-dependent manner: a new model of Takotsubo cardiomyopathy. Circulation. 2012;126:697-706.

Submit your next manuscript to BioMed Central and we will help you at every step:

- We accept pre-submission inquiries

- Our selector tool helps you to find the most relevant journal

- We provide round the clock customer support

- Convenient online submission

- Thorough peer review

- Inclusion in PubMed and all major indexing services

- Maximum visibility for your research 